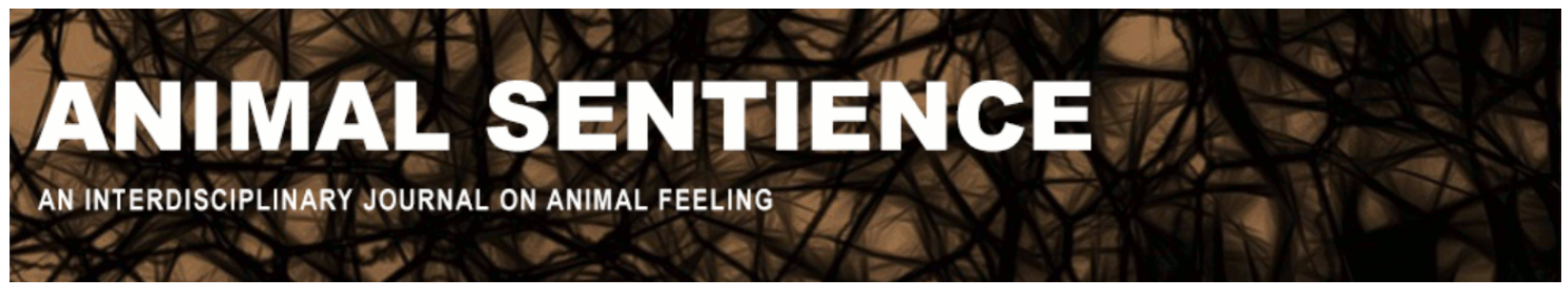

Rollin, Bernard E. (2016) Unity of consciousness in animals. Animal Sentience 10(8)

DOI: $10.51291 / 2377-7478.1151$

Date of submission: 2016-08-21

Date of acceptance: 2016-08-23

(c)

This article has appeared in the journal Animal

Sentience, a peer-reviewed journal on animal

cognition and feeling. It has been made open access,

free for all, by WellBeing International and deposited

in the WBI Studies Repository. For more information,

please contact

wbisr-info@wellbeingintl.org.

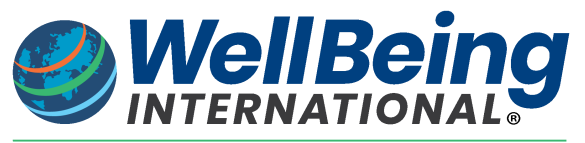

SOLUTIONS FOR PEOPLE, ANIMALS AND ENVIRONMENT 


\title{
Unity of consciousness in animals
}

Commentary on Rowlands on Animal Personhood

\author{
Bernard Rollin \\ Department of Philosophy \\ Colorado State University
}

\begin{abstract}
Both Descartes the rationalist and Hume the empiricist, polar opposites philosophically, denied the unity and continuity of animal mind. Kant pointed out that the presence of retrievable memories entails unity of consciousness. Rowlands now argues that animals too have unity of consciousness.
\end{abstract}

Bernard Rollin is Distinguished Professor of
Philosophy, Animal Sciences and Biomedical
Sciences, at Colorado State University. One of the
leading scholars in animal rights and animal
consciousness, he has lectured worldwide.
http://philosophy.colostate.edu/people/brollin/

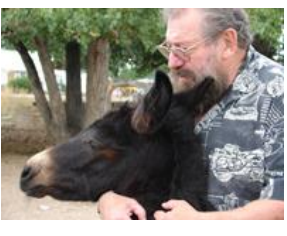

I am in virtually complete agreement with Rowland's analysis. I consider it to be very accurate, clear and wise. The major question he addresses is whether animals have a unified consciousness that endures over time. The first question that arises is why anyone would think they do not! Common sense would certainly not deny this.

The answer lies in a historical philosophical tradition beginning with Descartes, who saw animals as machines, on the clockwork model that became prominent in Europe during his lifetime. It is often asserted that Descartes had no actual experience with animals, otherwise he could never assert that they were merely machines. This claim is in fact historically false; Descartes is known to have raised spaniels and given them as gifts. The denial of mind to animals represented the convergence of multiple themes in Descartes's thought. In the first place, denial that animals had minds fit well with the Catholic belief that only human beings were gifted with an immortal soul. Second, as became clear in the linguistics of his followers at Port Royal, only human beings have language, and to study the human mind is to study language.

Descartes did much to usher in the Scientific Revolution that replaced the ancient metaphysics and epistemology of Aristotle based in sense experience with a denial of the reliability of sense experience and a highly mathematical worldview founded in reason. The cornerstone of Descartes's philosophy is the creation of a vast cleavage between mind and body ultimately based in the cogito - "I think therefore I am" - as the fundamental and indubitable item of knowledge. Seeing animals as operating strictly according to mechanical rules - biology as a branch of physics - also served to dispel the natural reluctance to cause pain to animals on 
the part of Cartesians who practiced vivisection (literally cutting up live animals) as travelers reported was done at Port Royal.

It is reported that Father Malebranche, one of Descartes's most prominent disciples, was in the habit of punctuating his lectures on Cartesian philosophy by kicking a pregnant mastiff who accompanied him to class vigorously in the abdomen, in order to stress to the horrified students that Descartes had delivered us from the misconception that animals can actually experience pain. (Incidentally, this view of animals as possessing no feelings or thoughts persisted through the $19^{\text {th }}$ century in France in the work of Claude Bernard and Louis Pasteur, and more generally in Continental thought, as evidenced by Spinoza and Kant.)

In many ways, the British empiricist tradition represented a major reaction to Descartes, particularly as instantiated in the work of David Hume. Hume was a fascinating philosopher in that his work embodied two distinct strands sometimes seen as incompatible. On the one hand, he was a thoroughgoing empiricist, greatly opposed to the notion, prominent in Descartes and other Rationalists, that one can gain any knowledge of the world by reason alone. For Hume, all that we know of the world is a result of our sense experience, or what Hume called complex impressions. These ultimately resolve down into simple impressions, instantaneous atoms of sensation, which, paradoxically, we never can experience, because, for example, temporality is derived from a series of impressions. On the other hand, Hume is very much a philosopher of common sense, affirming that as much as one tries to be a philosopher (i.e., an analytical metaphysician who reduces the world to the aforementioned sensory atoms), one must live in the world of ordinary experience. As Hume repeatedly puts it, "be a philosopher, but one must first be a man."

When it comes to animal mind, Hume is the polar opposite of Descartes. Rather than denying mind to animals, Hume affirms unequivocally that if people are conscious, so too are animals. Arguably the greatest skeptic in the history of philosophy, denying the ultimate knowability of mind, body, God, causation, the past or the future, Hume nonetheless extends no doubt to animal mind. In section XIV of the Treatise of Human Nature, "Of the Reason of Animals," he affirms "next to the ridicule of denying an evident truth, is that of taking much pains to defend it; and no truth appears to me more evident, than that beasts are endowed with thought and reason as well as men. The arguments are in this case so obvious, that they never escape the most stupid and ignorant." (The last sentence is presumably directed at Descartes.)

Ironically, Hume's skepticism extends even to our ability to know our own mind, rejecting Descartes's foundation. If, as he argues, all legitimate ideas are derived from impressions, i.e., from sensory experiences, then the idea of a unified mind must be derived from an experience as well. But when I look into myself, I find experiences of sleepiness, boredom, sensory perceptions, emotions, etc., but no continuing experience of "I," the self, or an enduring mind. Consequently, we must deny that there is an enduring mind - or, as Rowlands would put it, an enduring person. Rather, as Hume says, there is no such legitimate idea - it is rather "feigned." We treat what is in fact an ever-changing flow of experiences as an enduring entity, yet nothing could be more different. 
In other words, in his zeal to accept only experience as a basis for what we know of reality, and to avoid Descartes's postulation of an enduring self, Hume goes in the other direction and ends up affirming that there is no enduring subjective experience. Empiricism leads inexorably to skepticism! And the skepticism about an enduring mind extends as much to animals as to people. Thus, ironically, both Descartes the Rationalist, and Hume the empiricist, polar opposites philosophically, end up denying the unity and endurance of animal mind, albeit for very different reasons.

It took Immanuel Kant, operating unquestionably in a Cartesian tradition, but also confessing to having been "shocked out of his dogmatic slumber" by Hume's arguments, to resolve this conundrum with regard at least to the existence of an enduring human mind or consciousness. In what he called his "Copernican revolution," Kant turned a metaphysical question into an epistemological one, by the use of what he calls "transcendental argument."

Kant proceeds by, as it were, "burrowing beneath" Hume's arguments to what these arguments must presuppose. Even Hume acknowledged in the appendix to his magnum opus, $A$ Treatise of Human Nature, that he cannot reconcile the conflict between his argument that there is no unified mind, with his claim that "I" feign an enduring consciousness. After all, if his argument is correct, who is doing the feigning?

I will reconstruct Kant's argument in a way that is true to his way of reasoning. It may well be that our experience of the world is made up of atoms of experience. But what something is, is more than what it is made up of. For example, pancakes may be made of Bisquick, and coffee cake may also be made of Bisquick. But that does not mean that pancakes are identical to coffee cake. In other words, if we were to construct an equation with atoms of sensation on one side, and what we actually experience on the other, something else would be necessary to go from the atoms to the world of objects undergoing change and interaction. One such example is our awareness that when I look at Niagara Falls, for example, I must be the same individual who experiences the top of the Falls as the one who experiences the base. Similarly, when I experience a causal sequence such as striking a nail with a hammer, I must be the same consciousness who sees the hammer strike and who sees the nail penetrate. In other words, Kant takes Hume's apparent circularity regarding feigning the self and turns it into a logical presupposition of all experience. That is what a transcendental argument means for Kant something that necessarily must be present for any experience to be possible. Kant calls this the "transcendental unity of apperception," which simply means the unity of experiencer that must be present for there to be any continuous experience at all!

Where Kant goes wrong is in his claim that such a unity of apperception is present only in rational beings, and therefore absent in animals. As I will show, he has no basis for this claim - it is merely a remnant of medieval human exceptionalism. For everything that Kant says about human experience must be equally true of animal experience!

Animals, like humans, have ectypal intellects, the sorts of minds that depend on material that comes "from outside" through their sense organs. As Hume pointed out, sensory data in itself is not connected. But animals, like us, emerge with perceptions of enduring objects and extended causal interactions. When, for example, a lion runs to intercept a gazelle, it obviously 
has to be sufficiently self-aware to realize that it is the same entity that begins the chase as ends it when it does the kill. When the dog recalls that he has hidden a treat in a closet or buried a bone in the garden, he must be aware that he is the same entity now as when he did the hiding or burying. This point is endlessly exemplified in normal animal behavior. As Kant points out, the presence of retrievable memories entails unity of consciousness.

It is therefore extremely persuasive to argue, as does Rowlands, that animals have a unity of consciousness. Unfortunately, the issue of a unified consciousness is just one attack leveled against animal mind. Wittgenstein, for example, contrary to his commitment to the primacy of ordinary language, denied that animals can be said to have concepts; affirmed that if a lion could speak, we could not understand him; and that a dog cannot be said to hope. I am quite certain that all of these claims can be refuted, and are furthermore violations of common sense.

\section{Reference}

Rowlands, M. (2016) Are animals persons? Animal Sentience 2016.101 